\title{
Planning for Bike Share Connectivity to Rail Transit
}

\author{
Greg Phillip Griffin and Ipek Nese Sener \\ Texas A\&M Transportation Institute
}

\begin{abstract}
Bike sharing can play a role in providing access to transit stations and then to final destinations, but early implementation of these systems in North America has been opportunistic rather than strategic. This study evaluates local intermodal plan goals using trip data and associated infrastructure such as transit stops and bike share station locations in Austin, Texas, and Chicago, Illinois. Bike sharing use data from both cities suggest a weak relationship with existing rail stations that could be strengthened through collaborative, intermodal planning. The study suggests a planning framework and example language that could be tailored to help address the linkage between bike sharing and transit. Rather than an exhaustive study of the practice, this study provides evidence from these two cities that identify opportunities to improve intermodal planning. Cities that are planning or expanding a bike sharing system should consider carefully how to leverage this mode with existing modes of transport. Regardless of a city's status in implementing a bike sharing system, planners can leverage information on existing transport systems for planning at regional and local levels.
\end{abstract}

Keywords: Bike share; GIS; transit; plan evaluation; mixed methods

\section{Introduction}

Public transit is a critical component of sustainable transportation systems (Richter, Friman, and Gärling 2011), yet convenient last-mile access to and from transit stations is a persistent challenge for many communities (Cervero, Caldwell, and Cuellar 2013; Taylor and Hahmassani 1996). This restriction limits the utility of the mode for many urban dwellers, as well as access to jobs, goods, and services for those who do not have available other options such as personal automobiles. However, planning for transit station access can improve ridership and other performance measures over time (Boarnet and Compin 1999; Cervero and Gorham 2009).

Urban transit traditionally is accessed by any of the three other primary surface transportation modes. The most common is walking, but this mode is limited by distance, which affects the duration people are usually expected to walk to transit, 
often ranging between 500 meters and a kilometer, or approximately $1 / 4$ to $1 / 2$ mile (Crowley, Shalaby, and Zarei 2009). Most trips by public transit require either a mode switch or a route transfer to reach a desired destination. Through the siting of multiple routes at a single station, users can readily access a broader range of destinations. However, transfer times between routes depend on service headways, and this time adds to the barriers of transit use (Fan and Machemehl 2011). Personal vehicle access is another option, particularly at stations with areas for parking or kiss-and-ride service. Space needed for auto parking and access adds significantly to the cost of urban stations (Steiner et al. 2006; Pucher and Buehler 2009) and mitigates environmental and traffic benefits of transit service (Bartholomew and Ewing 2008). Finally, research on access to transit via bicycling indicates that it promises the sustainability benefits of walking while extending the effective access shed to a distance of 2 to 5 kilometers (1.2 to 3.1 miles), depending on the speed of the transit accessed (Krizek and Stonebraker 2010). In addition to distance, other barriers to bicycle transportation include perceived safety, exposure to weather, ownership of bicycles, and available secure parking (Hamre and Buehler 2014; Handy, Xing, and Buehler 2010; Mullan 2013; Orrick, Frick, and Ragland 2011; Twaddle, Hall, and Bracic 2010). Bike sharing provides at least a partial solution to the last two barriers.

Bike sharing is a relatively new mode that is increasing as a resource for urban trips and particularly as a connection to transit stations. The growth of bike sharing in areas served by transit offers the prospect to reduce the challenges some people may have in terms of time, comfort, and energy expenditure when trying to access a transit station (Ma, Liu, and Erdoğan 2015; Martin and Shaheen 2014). Bike sharing has the opportunity to serve as a feeder mode for the first and last mile of transit trips, potentially making transit and biking easier options to take more often, with mobility and health benefits for individuals and society (Demaio and Gifford 2004; DeMaio 2009; Duvall and Main 2012; Winters et al. 2010).

Despite its promising role in providing alternative solutions to access to transit stations and then to final destinations, there have been relatively few studies quantifying bike sharing's potential impact in facilitating transit trips. Recognizing this gap, this study aims at exploring the relationship between transportation planning goals related to bike sharing and transit, as well as variables of the local built environments affecting bike sharing ridership near transit. These topics are first explored through a review of previous studies on the combination of transit and bicycling. Then, bike share data from two central cities of United States are examined-Austin, Texas, and Chicago, Illinois. Both cities have growing bike share systems supported by significant planning efforts leading to recently improved bicycle networks, but not yet examined by earlier studies. Rather than direct comparison of Austin and Chicago, this study examined these two cities as a case study exploring key differences and similarities between them-particularly in key areas known to be related to bike sharing and transit. The next section focuses on the empirical and qualitative methods used in this study, before reporting the results and discussing implications to planning and transport geography. This paper concludes with a summary of contributions to planning for bike sharing and transit, in addition to needs for future study. 


\section{Potentials and Challenges of Bicycle Access to Transit}

Two recent studies explored the relationship between bike sharing and transit, each using different data and methods. Both pointed out the need to extend similar research, noting two distinct paths. Martin and Shaheen (2014) raised the need to explore builtenvironment variables in examining bike share behavior, and Ma et al. (2015) identified a need to consider the proximity of bike sharing to transit stations.

In particular, Martin and Shaheen's study (2014) focused on travel behavior change of bike share system members in Washington, DC, and Minneapolis, Minnesota. By mapping the location of survey responses, they found that users in less denselydeveloped areas often used bike share to access transit, as opposed to users in the dense urban core, who used bike share to get to transit faster and replaced some transit trips with bike share. A recent system-level analysis of Capital Bikeshare stations indicated that increasing bike-share trips by $10 \%$ would contribute to a $2.8 \%$ increase in Metrorail ridership (2015), suggesting bike share has a strong potential role as an access mode to and from transit trip ends. Both papers suggested that bike share can serve as a significant and complementary mode to extend the reach and effective speed of transit, but neither study considered the role of active planning of the system or the role of bicycle-specific infrastructure such as bike lanes.

Though bike sharing is a relatively new mode to be considered in the literature, several previous studies pointed out the importance of the bicycling environment on use of the mode. A recent study of bicycle-on-bus boardings from Cleveland, Ohio, suggested bike sharing at transit locations could help alleviate the crowding of transit systems related to on-board bicycles and conveyed the need for additional research on bicycling and transit (Flamm 2013). An analysis of Bay Area Rapid Transit stations supported this relationship as well, indicating that "cities with high transit usage and levels of cycling face on-board capacity constraints," which can be mitigated with bicycle parking and "bike sharing at destination stations" (Cervero et al. 2013, 102).

Facilities at destinations are only as accessible as the infrastructure that connects to them, however. Iseki and Tingstrom (2014) pointed out the importance of street connectivity to offer bicyclists a range of route choices, particularly to avoid steep hills, and noted that bicycle-specific infrastructure can play an especially significant role where vehicle traffic volumes or speeds are high. Similarly, transit ridership has been associated with street connectivity, but not necessarily tied to traditional, gridded street networks (Thompson et al. 2006). Using National Household Travel Survey (NHTS) data from 2001 and 2009, Wang and Liu (2013) showed that rail transit attracts similar rates of intermodal bicyclists to bus transit and emphasized the need to improve integration of the two modes to leverage the advantages of each. The literature points to a complementary relationship between bicycling and transit, with several recent contributions on planning supportive infrastructure.

Infrastructure plays a key role in both the perception and reality of safety for bicyclists. Sidewalks, bike lanes, and off-street paths facilitate more comfortable, safe travel for cyclists to destinations such as transit stops (Akar and Clifton 2009; Duthie et al. 2010; Iseki and Tingstrom 2014; Krizek, Handy, and Forsyth 2009). Surveys of bicyclists 
indicate that higher levels of on-street bicycle accommodations, such as protected bike lanes rather than wide curb lanes, are preferred for general transportation by both men and women (Dill et al. 2015), and specifically for accessing transit stations (Taylor and Hahmassani 1996). Ehrenfeucht and Loukaitou-Sideris (2010) place a normative responsibility for the provision of adequate infrastructure on planners, noting the need to create "'complete streets' for multi-modal transportation including sidewalks, crosswalks and bike lanes, as well as overhangs for weather protection, benches for sitting and trees for shade and comfort." Bike sharing is inherently intermodal, assuming at least a short walk to and from bike share stations and transit stops. Therefore, all three modes (walk, bike, and transit) require adequate provision for intermodal transitions to work well.

Bicycling and walking are critical parts of intermodal transit trips. Previous studies confirm the importance of the planning community to remain engaged in these issues from a holistic perspective, but also one that considers the needs of each local community to facilitate bike sharing as a supportive link to transit systems and destinations.

\section{Overview of Bike Sharing and Rail Transit in Austin and Chicago}

Many large North American cities have implemented bike sharing systems on an opportunistic basis-developed with available public and private funding without a strategic connection to existing transportation plans. The problem with this approach is that it may not leverage advantages particular to the bike sharing mode, particularly as a connection to high-capacity transit stations. This article explores this challenge through the cases of recent bike share program development in Austin, Texas, and Chicago, Illinois, and offers suggestions on how to better integrate urban transportation planning for existing and emergent modes.

Both Chicago and Austin have developed multimodal transportation systems and participated in transportation planning at the regional and local levels. Planning for bike sharing systems is a relatively nascent field, and these two cities are working toward rapidly growing their systems concurrent with integrated, multimodal transportation planning. Based on the most current and applicable plans at the regional and local levels, neither bike share systems share long range plans, but Chicago's Divvy system offers a map of expansion within the current year (2015). Since each bike share system is so new (both launched in 2013), only Austin's bicycle plan developed in 2014 refers to the bike share system explicitly. A cursory review of other city plans indicates similar findings: bike sharing systems emerged as a solution to broadly define bicycle transportation opportunities rather than prescriptive solutions, and bike sharing is more common in plans since their popularization after 2010.

Neither system's state-level plans address bike sharing explicitly. The Illinois Department of Transportation's 2014 statewide Bike Transportation Plan mentions bike sharing as "great way to encourage bicycle transportation," but it does not include bike sharing in any of its action items or objectives (Illinois Department of Transportation 2014). Currently, the Texas Department of Transportation's plans do not include bike sharing. 
News reports from El Paso, Texas, indicate the agency had denied support of that city's bike sharing system that had been approved by the metropolitan planning organization using federal congestion mitigation air quality (CMAQ) funding, but later supported a scaled-back bike share program (Lopez 2015). In Texas and Illinois, leadership in bike sharing planning has come from local and regional transportation partnerships.

Table 1 provides illustrative examples of goals and benchmarks related to bicycle infrastructure in general and bike sharing specifically for both Austin and Chicago.

TABLE 1. Illustrative Austin and Chicago Bicycle Transportation Planning Goals and Benchmarks

\begin{tabular}{|c|c|c|c|}
\hline & Plan & Bicycle Network & Bike Share System \\
\hline \multirow[t]{2}{*}{ Austin, TX } & $\begin{array}{l}\text { CAMPO } 2040 \text { Regional Transportation } \\
\text { Plan (Capital Area Metropolitan } \\
\text { Planning Organization, 2015) }\end{array}$ & $\begin{array}{l}\text { Strategy: "More Sidewalks and Designated Bicycle } \\
\text { Lanes" }\end{array}$ & Strategy: "Bike Sharing Programs" \\
\hline & $\begin{array}{l}2014 \text { Bicycle Master Plan (City of } \\
\text { Austin, 2014) }\end{array}$ & $\begin{array}{l}\text { "Complete } 20 \% \text { of the short-term all ages and } \\
\text { abilities network by } 2017,50 \% \text { by } 2020 \text {, and } 80 \% \\
\text { by } 2025 . "\end{array}$ & $\begin{array}{l}\text { "Expand Austin's bike share system } \\
\text { from } 40 \text { stations to } 100 \text { stations by } \\
2016 \text { and to } 300 \text { stations by } 2017 . "\end{array}$ \\
\hline \multirow[t]{3}{*}{ Chicago, IL } & $\begin{array}{l}\text { Chicago Streets for Cycling Plan } 2020 \\
\text { (Chicago Metropolitan Agency for } \\
\text { Planning, 2010) }\end{array}$ & $\begin{array}{l}\text { "Establish seamless coordination between } \\
\text { modes." }\end{array}$ & \\
\hline & $\begin{array}{l}\text { Bike } 2015 \text { Plan (Mayor's Bicycle } \\
\text { Advisory Council, 2006) }\end{array}$ & $\begin{array}{l}\text { "Goal: Provide convenient connections between } \\
\text { bicycling and transit." "Performance Measure: } \\
\text { Increase the number of bike-transit trips by } 10 \% \\
\text { per year." }\end{array}$ & \\
\hline & $\begin{array}{l}\text { Chicago Streets for Cycling Plan } \\
2020 \text { (Chicago Department of } \\
\text { Transportation, 2013) }\end{array}$ & $\begin{array}{l}\text { "Provide a bicycle accommodation within } 1 / 2 \text { mile } \\
\text { of every Chicagoan." "Provide a greater number } \\
\text { of bikeways where more people live." "Increase } \\
\text { the amount of infrastructure where ridership } \\
\text { is high, while establishing a strong backbone of } \\
\text { infrastructure where ridership is currently lower." }\end{array}$ & \\
\hline
\end{tabular}

As indicated in the table, the cities' goals and benchmarks are more specific in local plans, aligning with the strong responsibilities of cities versus regional planning bodies in the United States context. Though written before bike sharing implementation, Chicago's regional and local plans directly address the potential for bicycle and transit to facilitate travel options. Detailed valuation of planning outcomes will have to be done in the years ahead as performance measures are tracked and travel choices change over time. The present study is prospective in this regard, seeking to anticipate potential planning outcomes and relationships to improve planning for this relatively new mode of transport.

Density differences between the two cities play an important role in the effect of transportation options. In 2013, Chicago's population $(2,718,782)$ was just over three times that of Austin's $(885,400)$ (U.S. Census Bureau 2013b). The municipal boundary of Chicago is slightly smaller than Austin's, resulting in a city population density over 3.5 times greater. These differences in density also are reflected in the cities' transportation system planning over time. 
Both cities had streetcar systems by the end of the 19th century, which were abandoned as the automobile and bus systems were expanded-a typical pattern in American cities of the time (Brown, Morris, and Taylor 2009). Chicago's first elevated rail transit line opened in October 1897, followed by opening of subways in 1943 and 1951, the addition of rail service in the median of three expressways from 1958 to 1970, and rail service expansion to its airports in 1984 and 1993 (Chicago Transit Authority 2015). In contrast, Austin's single commuter rail line opened in 2010, and an urban rail funding plan was voted down in November 2014 (Tolbert 2014). Instead, Austin has several tolled expressways under development and could have as many as a dozen operational in the next decade (Wear 2014). Both cities have extensive suburbs with significant population, but bike sharing does not extend into them at present. Chicago and Austin's differences in density and transit options provide an extreme selection of cases that may "reveal more information" than cases that typify urban planning conditions (Flyvbjerg 2006, 229). Flyvbjerg suggests that the best cases for comparison include some variables that are similar; Chicago and Austin currently have identical bicycle commuting mode shares, as shown in Table 2.

TABLE 2.

Bike Share System and Commuting Descriptive Statistics

\begin{tabular}{|c|c|c|}
\hline Characteristics & Austin, TX & Chicago, IL \\
\hline \multicolumn{3}{|l|}{ Bike Share } \\
\hline Bike share station count, August 2015 (O'Brien 2015) & 50 & 474 \\
\hline Active bike share docks, August 2015 (O'Brien 2015) & 635 & 7,933 \\
\hline Gender-female members (Opinion Analysts Inc. 2014; Vance 2014) & $35.5 \%$ & $35.7 \%$ \\
\hline $\begin{array}{l}\text { Using bike share to connect to transit }{ }^{1} \text { (City of Chicago 2014; } \\
\text { Opinion Analysts Inc. 2014) }\end{array}$ & $48 \%$ & $76 \%$ \\
\hline \multicolumn{3}{|l|}{ City Commuter } \\
\hline Workers 16 years and over (U.S. Census Bureau 2013a) & 482,918 & $1,245,739$ \\
\hline Commute means: Car, truck or van (U.S. Census Bureau 2013a) & $83.6 \%$ & $58.2 \%$ \\
\hline Commute means: Public transportation (U.S. Census Bureau 2013a) & $4.2 \%$ & $27.8 \%$ \\
\hline Commute means: Bicycle (U.S. Census Bureau 2013a) & $1.4 \%$ & $1.4 \%$ \\
\hline
\end{tabular}

${ }^{1}$ Survey questions between the cities differed. Austin B-cycle's member survey asked whether availability of the B-cycle bike sharing programing make it more likely that you will use the bus or train than if it were not available. Chicago Divvy's response refers to whether members "sometimes" or "often" use Divvy for the purpose of going to or from transit.

Table 2 also shows that Chicago's bike share system is much larger, with more than six times the number of stations and bicycles in Austin. Analysis of both cities affords a view of the relationship between bike sharing and transit at very different scales: Chicago's very large and mature transit system is quickly interfacing with a new bike share system, and Austin is adding bike sharing simultaneously with the development of a small but growing rapid transit system. In this study, each city varies widely in its historical urban transportation approaches, but the extent of intermodal planning regarding bike sharing are relatively similar.

Chicago's extensive transit system plays a major role in a significant reduction of automobile trips, yet the two cities share the same bicycle commute rate of $1.4 \%$ of 
persons reporting that they usually get to work in the previous week by biking, as reported in American Community Survey (ACS) statistics (U.S. Census Bureau 2013a). It should be noted that bicycling trips reported via this commute statistic are a small portion of all bicycle trips, since trips to school, shopping, or all other purposes are omitted.

Literature on the role of intermodal support or competition between bike sharing and transit is inconclusive. Initial studies suggest substitution of some shorter bus trips with bike sharing and a more symbiotic relationship with rail transit (Ma et al. 2015; Martin and Shaheen 2014). In addition to the general positive association between Metrorail ridership and Capital Bikeshare use (Ma et al. 2015), survey results from Minneapolis and Washington, DC suggest these relationships vary by city and neighborhood. Bike sharing may foster new connections to transit in less dense areas than in very dense locations that more often are served by passenger rail (Martin and Shaheen 2014). Rather than focusing on causal relationships of mode substitution, the data and methods in this study support analysis of planning that could foster intermodal support in the future.

Fully intermodal transportation planning considers the mobility needs of all users for all purposes, but this study focuses on bike sharing and rail transit. Our preliminary analysis of bus stop locations in proximity of bike share stations revealed a nearly ubiquitous relationship, one that will offer no useful differentiation in spatial analysis for the present case studies. Rail transit offers a special relationship with bike sharing, where the shortcoming of rail's high speed and distance between stations can be served well with bike sharing to solve the well-researched last-mile problem. In addition, rail station locations are relatively permanent, implying impacts on long-range planning of both land use and transportation. Bus stops and routes are relatively transient in comparison, which can confound extension of analysis over the longer term.

\section{Data and Methods}

This study takes a mixed methods approach to evaluating the opportunity for bike share systems to improve first and last mile rail transit access, using descriptive statistics, plan evaluation techniques, and semi-structured interviews of bike share system planners. First, bike share use data from the two relatively young systems with proximity to rail transit are analyzed, and then each city's planning performance measures related to the two modes is evaluated.

Bike share trips are recorded and disseminated by operators on a per-trip basis, often with unique bicycle numbers, and to and from station locations for each trip, excluding personally-identifiable information of the users. These tables were summarized by counts in a given time period, then joined to a spatial database of bike share station locations for further analysis. This allowed spatial analysis of bike share data with proximity to each city's rail transit stations and density measures from the Environmental Protection Agency's Smart Location Database (Ramsey and Bell 2014).

In addition to the basic system statistics in Table 2, spatial statistics were calculated to provide additional insights on the systems characteristics. Average nearest-neighbor statistics reveal Austin B-cycle's smaller system is also closer together, at an average of 1,035 feet between stations versus 1,615 feet for Chicago's Divvy system. Both were 
calculated using a Manhattan distance (along $\mathrm{x}$ and $\mathrm{y}$ axes) to approximate urban navigation, recognizing that bicycle travel allows crossing parking lots and plazas rather than being fully bound to city streets or paths. These existing spatial datasets were then reviewed alongside planning documents from each city.

Plan evaluation focused on evaluation of goals to each city's published documents related to bicycle planning. Plan evaluation is typically conducted as an entire document using content analysis methods (Stevens, Lyles, and Berke 2014; Stevens 2013), but the focus of this study is on the planning goals and benchmarks (also sometimes called performance measures) related to bicycle infrastructure and, in particular, bike sharing systems. The content of plans often omits experiences and perspectives of the planners themselves, however, and interviews can help reveal otherwise unrecorded details.

Semi-structured interviews were arranged with a primary bike share planner for each system. Local planners recommended key informants, and their anonymity was maintained to promote individual perspectives. Interviews were conducted using computer-based internet messaging software, offering a standardized interview environment appropriate for professionals experienced with online tools but lacking non-verbal information present in face-to-face interviews (Brabham 2010). The interview plan for each informant included six questions designed to be answerable in a halfhour session, including time for additional discussion. This mixed-method case-study approach provided a basis for context-dependent knowledge that is more valuable for analysis of human affairs than the search for "general, theoretical knowledge" that might support "predictive theories and universals" (Flyvbjerg 2006, 224).

To analyze each case of bike sharing and transit, bike station use volumes and urban densities at a station level were reviewed, and then considered proximity of bike stations to transit. These quantitative results suggested the current relationships between the modes, using measures supported by the review of literature. Survey results from each station offered additional quantitative results from users. Planning documents at multiple levels of government were reviewed to identify the extent to which the two modes have been planned in any integrated fashion. Finally, the semi-structured interviews filled gaps in understanding the planning process and suggested directions for improving intermodal planning.

\section{Results}

\section{Bike Station Use and Density of Population and Employment}

Figure 1 maps bike share trip counts for each city in the second quarter of 2014, with each city's respective activity density displayed as jobs and housing units per acre. Both bike share systems do not yet serve either city's extent of dense areas. In addition, Figure 1 shows that the bike share activity does not significantly decline towards the outer edges of either system, suggesting that neither system has spatially expanded as far as its density may support. The highest volume bike share stations are not necessarily located near the rail transit stations shown on the map, suggesting that either there is little natural relationship between the two or, perhaps, the relationship has yet to have been realizedwhich may be addressed through planning and implementation of targeted solutions. 
FIGURE 1.

Bike share trip counts, 2nd quarter 2014, and development density
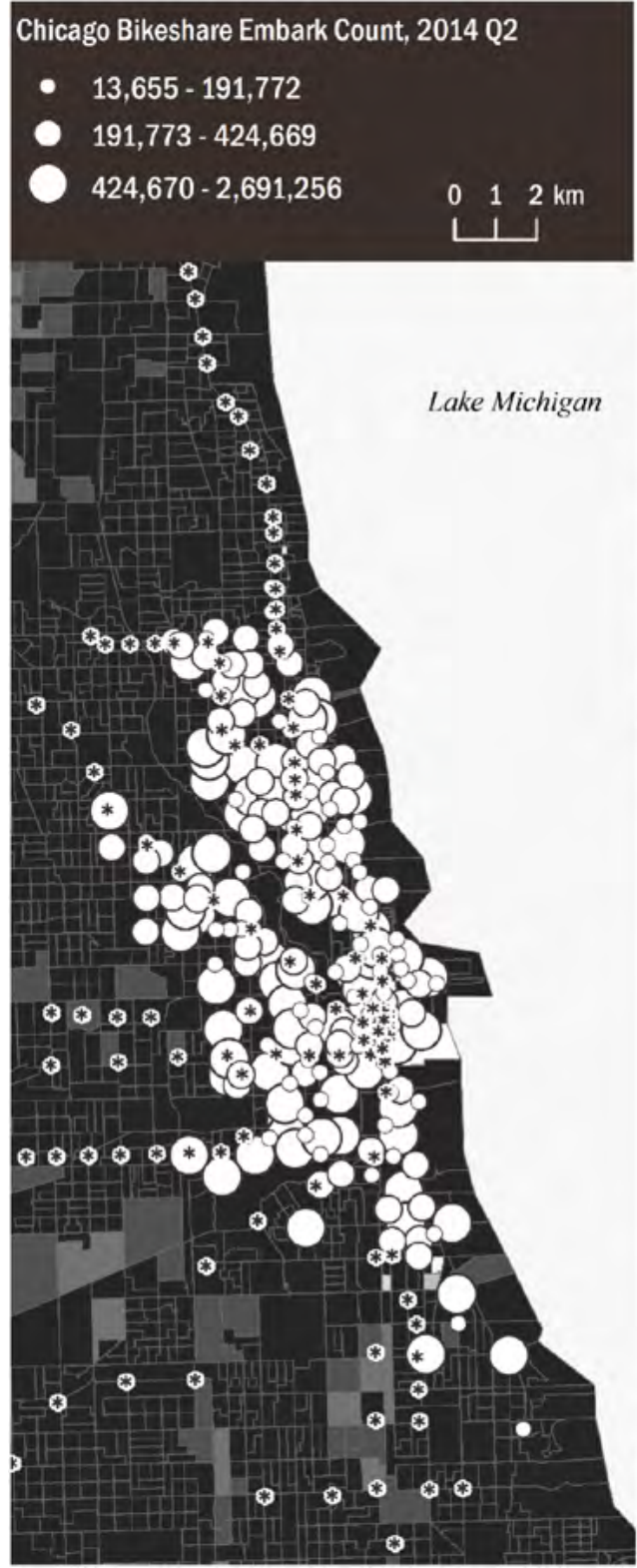

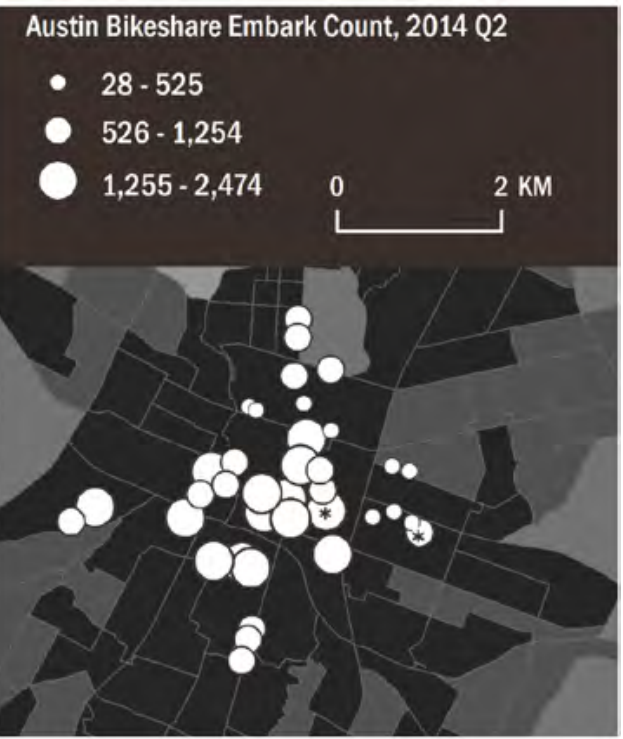

Jobs + Housing Units/Acre

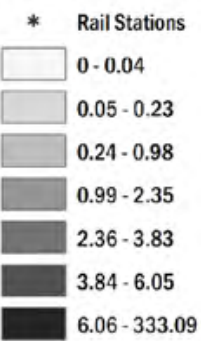

\section{Relationship of Proximity of Bike Share Volumes to Transit}

Analysis of trips over the duration of the brief bike share systems' lives reveals little apparent interaction with transit ridership at the system-level. Figure 2 shows the first 18 months of bike share system operation in Chicago. Divvy operates year-round, and use fluctuates strongly with the seasons. Colder climates have been shown to have a strong relationship with bicycling in previous studies (Heinen, Maat, and van Wee 2011; Mahmoud, El-Assi, and Habib 2015). Chicago's bus and rail modes roughly parallel each other, with monthly volumes ranging between 17 million and 27 million, respectively. Overall transit mode use in 2013 and 2014 was relatively stable or slightly declining. However, bike share system use nearly doubled from October 2013 to the same time a year later, despite a lack of growth in the number of stations over this time. 
FIGURE 2.

Chicago transit and bike share ridership, 2013-2014

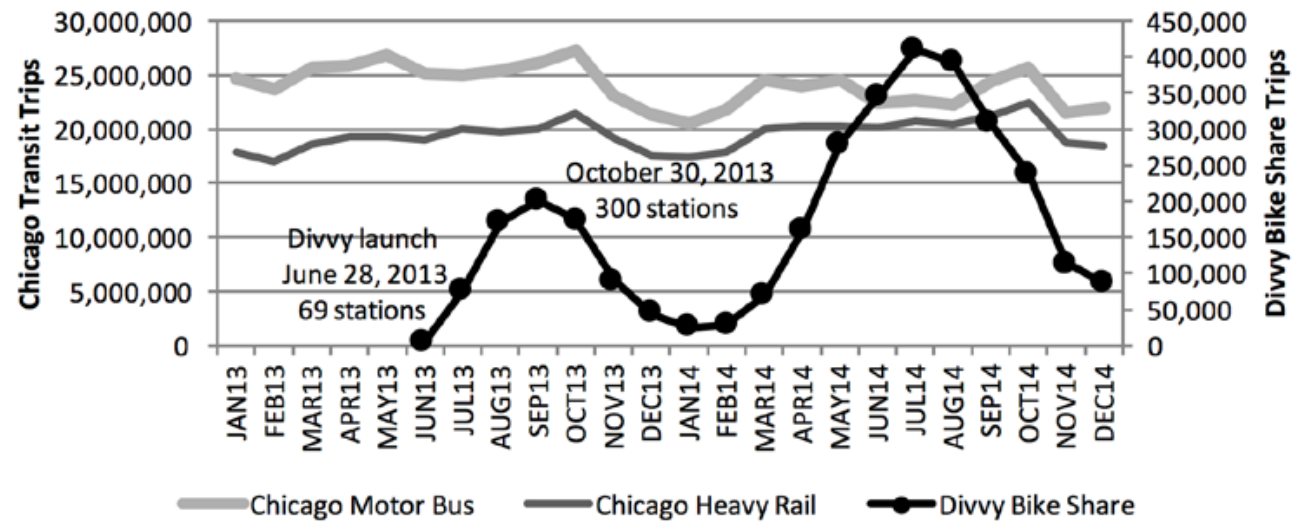

Figure 2 suggests very little substitution effect at the system level, a finding consistent with a recent study of Divvy trips that showed a positive correlation of annual bike share trips from stations within 300 meters from a rail station, but the opposite relationship with day-use customers (Faghih-Imani and Eluru 2015b). This is an intuitive relationship-Divvy system users who chain intermodal trips with rail for regular trips would be expected to more likely choose an annual membership. The converse of this is that occasional or tourist uses of Divvy may be more likely to use the system for direct access to destinations. Since Divvy launched in June 2013, the first full year of operation was 2014, providing users with the opportunity to use the system as soon in the year as they desired. As Divvy continues to expand, growth in its use could be expected to level off, at which time additional empirical analysis of trip volumes with transit may be more appropriate.

Austin has a very different transit context, with a single commuter rail line serving nine stations and a bike share system composed of 50 stations tightly dispersed in a loose cross formation centered on downtown (as of 2015). Figure 3 shows the limited data available from Austin's B-cycle system since its launch in December 2013. The relatively small size of Austin's system is strained during large special events, such as the South by Southwest (SXSW) Festival held every March in Austin. The operator reports "On Friday, March 14, it set a U.S. system record of 2,774 checkouts for an average of 10.1 checkouts per bike/day, besting the previous record in September 2013 of 7.2 checkouts per bike/ day set by the successful New York City Citi Bike program" (Austin B-cycle 2014). Austin transit and bike sharing systems also are likely affected by the seasonality of local colleges and universities, anchored by The University of Texas at Austin with more than 51,000 students enrolled. 
FIGURE 3.

Austin transit and bike share ridership, 2013-2014

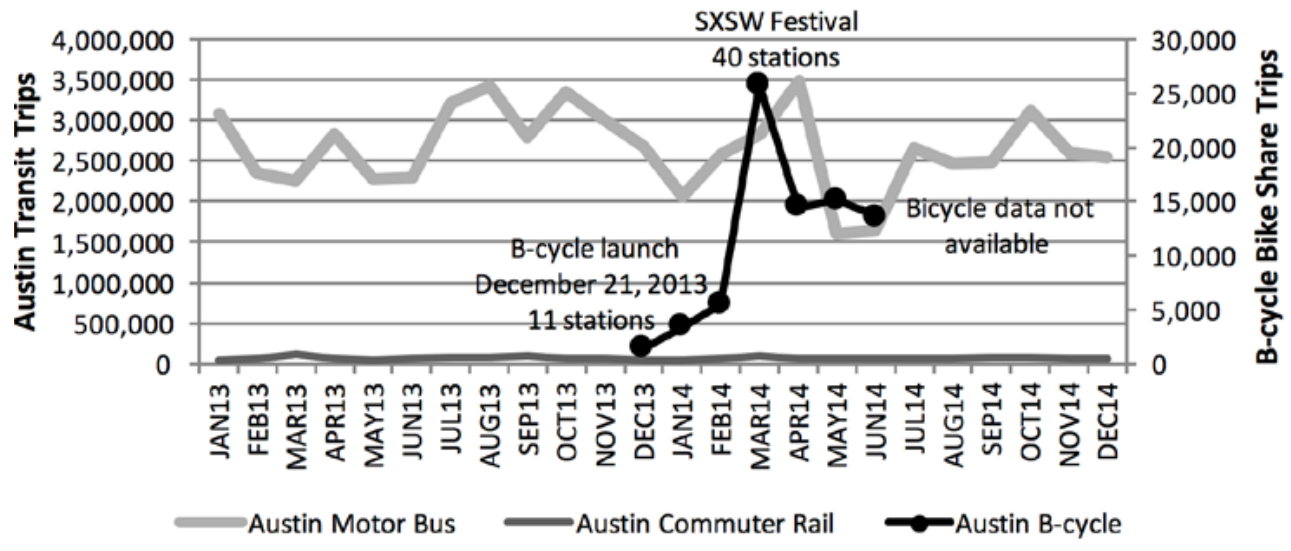

More than three-quarters of Austin's bike share trips were taken with 24-hour passes, whereas a little more than half of Chicago's bike share trips used daily passes. Many factors, such as membership policies, costs, and local economics, likely play a role, but Austin's younger system age might play a role as well-people may be more likely to try the system in the first year with daily passes and consider membership at a later date. The SXSW Festival is a major factor in Austin, with 38.3\% of survey respondents reporting that they used B-cycle at SXSW, $96.7 \%$ of whom used 24 -hour B-cycle passes (Opinion Analysts Inc. 2014). Regardless, this factor should be considered in bike share system planning, with recent research supporting analysis for reallocation of stations during high tourism months (Faghih-Imani and Eluru 2015a).

Analysis of both cities' bike share embarks shows that just under half are within 400 meters from a rail station, a maximum distance suggested by operators for spacing between bike share stations (Shaheen, Cohen, and Martin 2013). Chicago's extensive rail station coverage, shown in Figure 1, covers about half of the Divvy stations across the city. As shown in Table 3, 47\% of Austin's bike share embarks are within 400 meters from a passenger station, but the city has only two rail stations near the B-cycle service area. The small size of the system, however, limits statistical evaluation of local conditions that may be fostering this relationship. Indeed, the currently small system does not serve areas far from the central business district.

Mean Bike Share Embarks Near and Far from Passenger Rail Stations

\begin{tabular}{|l|c|c|}
\hline & $\begin{array}{c}<400 \text { Meters from Passenger Rail } \\
\text { Station (\% of total embarks) }\end{array}$ & $\begin{array}{c}>400 \text { Meters from Passenger Rail } \\
\text { Station (\% of total embarks) }\end{array}$ \\
\hline Austin, TX & $957(46.9 \%)$ & $1,083(53.0 \%)$ \\
\hline Chicago, IL & $360,165(44.6 \%)$ & $447,256(55.4 \%)$ \\
\hline
\end{tabular}

\section{Bike Share System Surveys}

Both systems also have surveyed users about their use of bike share, but differences between the questions asked limit comparison of the systems using this source. As shown in Table 2, 76\% of Divvy members surveyed in January 2014 reported using bike share to travel to or from transit "sometimes" or "often" (City of Chicago 2014). Austin $B$-cycle asked a sample of members and non-member users two questions related to transit. A total of $48 \%$ reported that the B-cycle system makes them more likely to 
use transit than if it were not available (Opinion Analysts Inc. 2014), and 9\% said they replaced a bus or rail transit trip with B-cycle the last time they used the system. These results indicate that bike share users report a two-sided relationship with transit-it may help provide access to transit stops, and it also can replace some transit trips. Insights from the survey of each bike share system are only partially supported by the cities' planning goals at present and may be helpful in guiding further advancements.

\section{Evaluating System Planning Goals}

The Austin region's current draft transportation plan aims to improve active transportation with a strategy to add "more sidewalks and designated bicycle lanes" and to add or expand bike sharing programs. The plan uses soft language to target only $15 \%$ of available CAMPO discretionary federal funding under the Surface Transportation Program-Metropolitan Mobility (STP-MM) program to bicycle and pedestrian projects (Capital Area Metropolitan Planning Organization 2015, 220), whereas the previous regional plan set this value as the minimum. Since STP-MM was used for the initial development of Austin B-cycle, this policy change could counter its own stated strategies to improve healthy mobility with active transportation improvements. The local plan from the City of Austin maybe one of the first to explicitly incorporate specific bike sharing expansion goals in its planning, stating its desire to "Expand Austin's bike share system from 40 stations to 100 stations by 2016 and to 300 stations by 2017." To be most effective, plans should offer both a specific objective to achieve a goal and a likely funding mechanism to reach it.

Chicago's municipal and regional plans had not been updated recently enough to consider bike share as part of the transportation plan explicitly, but the documents had highlighted the importance of the bicycle mode to connect and extend transit service. Though written nearly a decade before launching the city's bike share system, Chicago's bike plan goal to "Provide convenient connections between bicycling and transit" (Mayor's Bicycle Advisory Council 2006, 20) is served by the current bike share system, as are additional improvements to the bicycle network such as adding protected bike lanes on existing roadways and adding safe and comfortable bicycle access to transit stations. The Chicago bike plan lays out five objectives to achieve this goal, with specific strategies and performance measures to achieve them. Possible funding sources are listed for each objective, strengthening likely implementation of this plan. Chicago's Bike 2015 Plan was developed to be comprehensive, clear, and achievable, but the current Streets for Cycling 2020 plan (Chicago Department of Transportation 2013) is focused on improving the network without its predecessor's broad perspective.

Each city's strong goals and planning shortcomings reflect a desire to increase use of the bicycling mode-bike share systems and transit service are seen as positive complements to each city's cycling goals, leading to implications for improving nextgeneration planning. Both cities leave visible gaps in their approaches to integrating bike share and transit planning reflected in the planning documents, but the actual bike share station planners have additional knowledge about the processes. 


\section{Semi-structured Interviews}

Interview questions with each system planner spanned across how the public was involved in the process; how locations were actually decided, including addressing conflicts; and considerations of rail transit and collaborative planning. Planning of both systems included analysis of objective data on bike facilities, parks, entertainment, employment density, future development, and physical barriers to cycling. Each of them also included an online public participation geographic information system (PPGIS) to gather citizen ideas on where stations should be located. The Austin planner reported that every suggested location within the area covered by its grant (through the United States' Surface Transportation Program-Metropolitan Mobility) was taken into account and that most of them were clustered in the same areas, similar to restrictions noted by the planner for Divvy. The planner that worked on the Chicago system reported combining in-person public engagement with the online platform by "ask[ing] people to access the online platform at the in-person meetings." The PPGIS method for bike share planning was described as being different from other experiences:

There is a very concrete task that the public can help with, specifically, where is best to site bike share stations? With other planning or infrastructure projects, you need feedback on "issues," and then the planners interpret it.

The public suggestions for bike share locations were analyzed by the planners in terms of roadway compatibility between stations and construction feasibility that considered issues such as public right-of-way, sidewalk accessibility requirements, and utilities. Though Austin's planner did not respond directly to the question about planning with rail transit, Chicago's planner reported considering proximity and frequency of transit as a factor in the initial suitability analysis and that their planning effort included "a bike share station at every fixed rail stop." Both systems ended up placing large-capacity bike share locations near their busiest transit stations. Neither system planner reported any existing guidance that could help them develop the bike share plan in an integrated manner with rail transit.

\section{Discussion}

\section{Implications for Bike Share System Planning}

Bike share systems vary in their relationship to centralized transportation planning authorities. In most cases, however, cities and regional planning bodies work closely with bike share operators, and often subsidize capital and, less often, operating costs. This leads to some natural variation in how effective cities may be in fostering growth of bike share systems and their role in complementing transit. The evidence presented in this study suggests that bike share system planning for connectivity to transit should address system-level policies, a strong tie between strategic planning and measurable implementation and a nuanced, highly-local approach for station placement and network improvements.

The variance of planning policies in these two cities reflects both a rapid advancement in the role of bike sharing and suggests a lack of planning between modes, perhaps constrained by funding silos and bureaucracy. Indeed, the growth of urban bike 
sharing systems is a global phenomenon, yet the system of laws and funding control in American cities is highly local (Rodriguez and Shoked 2014). Rodriguez and Shoked (2014) suggest that policy development through the bike share planning process tend to underplay the importance of specific funding mechanisms, and this oversight has led to several systems' poor financial footing and subsequent restructuring. They indicate this could be mitigated through local separation of powers, where a strong mayor's role in policymaking and funding allocation could be reconsidered to improve urban policymaking. Austin and Chicago share a rapid turnover in agency leadership at the city and county levels that tend to trickle over into the boards of metropolitan planning organizations and transit agencies, leading to a valuable staff role in the development, implementation, and monitoring of transportation plans.

Analysis of bike share use and built environment variables support the role of knowledgeable staff and robust public involvement in planning of bike share kiosk placement and the subsequent connections to transit service. In terms of bike share kiosk placement, planners need to consider many complex site-level needs including and beyond the variables in this study, including land ownership, neighborhood desires, and sight distance. This approach is a diversion from previous studies that looked primarily at system-level statistics (Fishman, Washington, and Haworth 2013). However, small-scale analysis is both an advantage and a limitation of this study.

\section{Toward a Framework for Integrated Bike Share and Transit Planning}

This study's review of planning for bike sharing and transit in Austin and Chicago suggests that, to date, each city's approach to the modes have been relatively fragmented. Only Austin's most recent (2014) bike plan addresses bike sharing, and it does not strategically tie the importance of this mode to the region's transit planning. Grounded in John Dewey's pragmatism that influenced engineering sciences and the communicative action theory of Jürgen Habermas associated with social mobilization, this framework is positioned within the mainstream of theories for transportation planning (Friedmann 1987; R. Willson 2001). Figure 4 suggests an approach in which transit planning incorporates bike share and network planning by regional and local agencies in partnership with the bike share provider, recognizing that it can be public or private, within an umbrella agency, or on its own. Similar to current transportation planning concepts that rely heavily on public participation as well as expert-identified needs (Brooks 2002; Willson, Payne, and Smith 2003), the process starts with a simultaneous assessment of needs from both perspectives. The cross-disciplinary team then formulates goals to address the transit access issues found in the first step. Specific strategies then need to be developed, again leaning heavily on a partnership with the local bike sharing provider to work proactively towards the shared goals. Performance measurement and public participation extend the process throughout implementation of the bike sharing and transit development process, providing feedback to the original assessment of needs; an annual revisiting schedule is suggested. 
FIGURE 4.

Planning framework for integrated bike share and transit planning

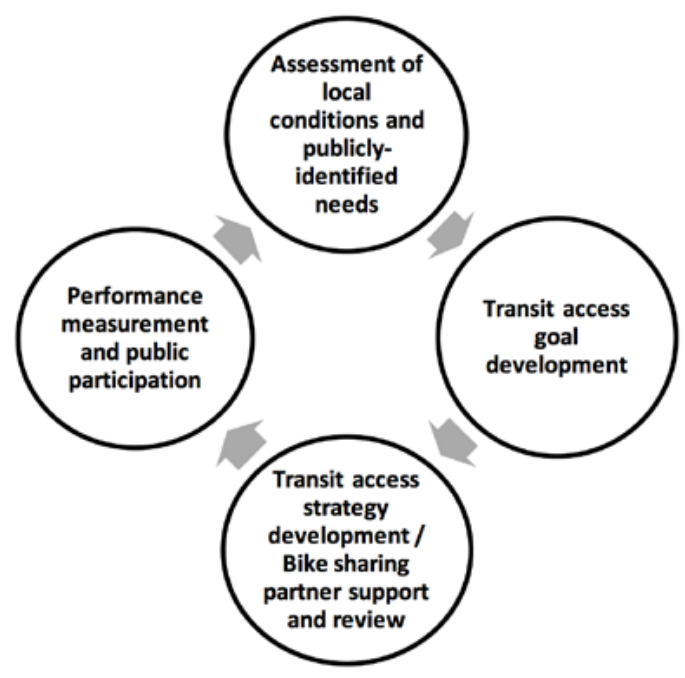

The general framework presented in Figure 4 can help define partners and processes, but specific language sometimes is needed to help guide how different agencies can best work together. Table 4 suggests some examples of goals, strategies, and performance measures that could be tailored to local needs, demonstrating at least one potential method to work towards a plan that addresses the gap between bike share development and long-and-short-range transit planning.

TABLE 4. Example Language for Integrated Bike Share and Transit Planning

\begin{tabular}{|c|c|c|c|}
\hline Plan Type & & Bicycle Network & Bike Share System \\
\hline \multirow{3}{*}{$\begin{array}{l}\text { Long Range } \\
\text { Transportation Plan } \\
\text { (LRTP) }\end{array}$} & Goal & $\begin{array}{l}\text { [X\%] of regionally-significant roads include a } \\
\text { bicycle accommodation }{ }^{1} \text { by [date]. }\end{array}$ & $\begin{array}{l}\text { Bike sharing is accessible at [ } \mathrm{X} \text { number] } \\
\text { of regional transit stations by [date]. }\end{array}$ \\
\hline & Strategy & $\begin{array}{l}\text { Include bicycle accommodations } 1 \text { on new } \\
\text { and reconstructed, regionally-significant } \\
\text { roads within [ } X \text { distance] of transit stations } \\
\text { by [date]. }\end{array}$ & $\begin{array}{l}\text { Support implementation of bike } \\
\text { sharing systems near transit } \\
\text { stops through available surface } \\
\text { transportation funding. }\end{array}$ \\
\hline & $\begin{array}{l}\text { Performance } \\
\text { Measure (data } \\
\text { source) }\end{array}$ & $\begin{array}{l}\% \text { of new and reconstructed road centerline } \\
\text { miles with bicycle accommodations } \\
\text { within [X distance] of transit stations } \\
\text { (Transportation Improvement Program). }\end{array}$ & $\begin{array}{l}\% \text { of available surface transportation } \\
\text { funding (Transportation Improvement } \\
\text { Program); [X number] of regional } \\
\text { transit stations with bike share access } \\
\text { (regional information system) }\end{array}$ \\
\hline \multirow[t]{3}{*}{$\begin{array}{l}\text { Transit service or city } \\
\text { transportation plan }\end{array}$} & Goal & $\begin{array}{l}\text { [X\%] of collector streets include a bicycle } \\
\text { accommodation }{ }^{1} \text { by [date]. }\end{array}$ & $\begin{array}{l}\text { Bike sharing is accessible at [ } \mathrm{X} \text { number] } \\
\text { of local transit stops by [date]. }\end{array}$ \\
\hline & Strategy & $\begin{array}{l}\text { Street resurfacing and construction includes } \\
\text { bicycle accommodations }{ }^{1} \text { on collector streets } \\
\text { within }[X \text { distance] of transit stations by } \\
\text { [date]. }\end{array}$ & $\begin{array}{l}\text { Support implementation of bike } \\
\text { sharing systems near transit stops } \\
\text { through available local funding. }\end{array}$ \\
\hline & $\begin{array}{l}\text { Performance } \\
\text { Measure (data } \\
\text { source) }\end{array}$ & $\begin{array}{l}\text { \% of new and resurfaced collector centerline } \\
\text { miles with bicycle accommodations within } \\
\text { [X distance] of transit stations (Capital } \\
\text { Improvement Program). }\end{array}$ & $\begin{array}{l}\text { [X number] of local transit stops with } \\
\text { bike share access (local information } \\
\text { system). }\end{array}$ \\
\hline
\end{tabular}

${ }^{1}$ Reference locally-developed or adopted standards for bicycle accommodation, such as American Association of State Highway and Transportation Officials 2012; Institute of Transportation Engineers 2010; National Association of City Transportation Officials 2014. 


\section{Limitations of Data and Multi-City Comparisons}

Since both cities' systems are relatively new, this study incorporates a limited dataset. Public response to system changes can be expected to fluctuate, though not necessarily in predictable ways. Changes in payment or other operational characteristics, outreach to low-income communities, and other service improvements may change the relationships presented in this study.

Though Chicago and Austin are geographically located near the center of the U.S., the sheer size of their populations and transit systems limit their direct comparability in terms of transportation system performance. Rather than focusing on comparing these cities, this study provides these examples for future longitudinal studies, as well as potential benchmarks for comparing other bike share systems. Replication of methods in this study in other locations and over time could lead to further support or variances from our conclusions.

\section{Conclusions}

Among the primary surface transportation modes of walking, biking, automobile, and bus and rail transit, the latter is distinguished by its access only at designated stops and stations. This study analyzed the content of transportation plans in Austin and Chicago for goals related to bike share and transit modes and analyzed bike share use volumes in the two cities in 2014. Analysis of planning documents indicated opportunity to extend planning processes across the bicycling and transit modes at both the municipal and regional planning scales. Semi-structured interviews suggested a valuable role in public engagement, supported using an online location suggestion map, and pointed out a lack of guidance in integrated planning.

The rapid changeover in agency leadership and their roles in implementing bike share systems are implicated in system planning and implementation challenges, which planning staff may be able to partially mitigate through engaging with political leadership and by fostering effective public participation. Though many bike share systems are under development throughout the world, many opportunities exist to improve their planning and integration with transportation systems at the regional and neighborhood levels. This study introduced the need to address the issues from a broad perspective while developing partnerships for effective planning between bike share companies, transportation agencies, and the public.

This study used a mixed-methods dataset, combining empirical data from each bike share operator with review of planning documents and semi-structured interviews with system planners. The planning of bike sharing in conjunction with passenger rail stations may leverage each of their advantages, but the role of bus transit and bike sharing should be analyzed in future studies. Particularly as bus rapid transit (BRT) planning has grown in recent years, there are many opportunities to research how planning can be improved for these modes. 


\section{Acknowledgments}

This research was motivated and in part supported by the National Institute of Diabetes and Digestive and Kidney Diseases of the National Institutes of Health under Award Number R01DK101593. The content is solely the responsibility of the authors and does not necessarily represent the official views of the National Institutes of Health. The authors appreciate Austin B-Cycle data provided by the system's Executive Director, Elliott McFadden, in additon to the system planners who shared their insights through interviews. The authors would like to acknowledge the valuable comments of three anonymous reviewers on an earlier version of this paper. The second author would like to dedicate her part of the research efforts to the memory of her dear father, Erdinc Sener, who passed away in October 2015.

\section{References}

Akar, G., and K. Clifton. 2009. "Influence of Individual Perceptions and Bicycle Infrastructure on Decision to Bike." Transportation Research Record, 2140: 165-172. doi:10.3141/2140-18.

American Association of State Highway and Transportation Officials (AASHTO). 2012. Guide for the Development of Bicycle Facilities (4th ed., Vol. 7). Washington, DC: AASHTO.

Austin B-cycle. 2014. "Austin B-cycle Sets U.S. Bikeshare System Record." https://www.bcycle.com/buzz/2014/10/05/austin-b-cycle-sets-u.s.-bikesharesystem-record, retrieved March 5, 2015.

Bartholomew, K., and R. Ewing. 2008. "Land Use-Transportation Scenarios and Future Vehicle Travel and Land Consumption: A Meta-Analysis." Journal of the American Planning Association, 75(1): 13-27. doi:10.1080/01944360802508726.

Boarnet, M. G., and N. S. Compin. 1999. "Transit-Oriented Development in San Diego County." Journal of the American Planning Association, 65(1): 80-95. doi:10.1080/01944369908976035.

Brabham, D. C. 2010. "Crowdsourcing as a Model for Problem Solving: Leveraging the Collective Intelligence of Online Communities for Public Good." Dissertation, University of Utah.

Brooks, M. P. 2002. “Feedback Strategy of Public Planning." In Planning Theory for Practicioners. Chicago: IL: Planners Press, American Planning Association.

Brown, J. R., E. A. Morris, and B. D. Taylor. 2009. "Planning for Cars in Cities: Planners, Engineers, and Freeways in the 20th Century." Journal of the American Planning Association, 75(2): 161-177. doi:10.1080/01944360802640016.

Capital Area Metropolitan Planning Organization. 2015. CAMPO 2040 Regional Transportation Plan. Austin, TX.

Cervero, R., B. Caldwell, and J. Cuellar. 2013. "Bike-and-Ride: Buid It and They Will Come." Journal of Public Transportation, 16(4): 83-105. 
Cervero, R., and R. Gorham. 2009. "Commuting in Transit versus Automobile Neighborhoods." Journal of the American Planning Association, 61(2): 210-225. doi:10.1080/01944369508975634

Chicago Department of Transportation. 2013. Chicago Streets for Cycling Plan 2020. Chicago, IL.

Chicago Metropolitan Agency for Planning. 2010. GO TO 2040. Chicago: IL.

Chicago Transit Authority. 2015. CTA Facts at a Glance. http://www.transitchicago.com/ about/facts.aspx, retrieved May 20, 2012.

City of Austin. 2014. 2014 Bicycle Master Plan. Austin, TX.

City of Chicago. 2014. "Survey of Divvy Members Brings Positive Reviews of Chicago's Newest Transit Service." http://www.cityofchicago.org/city/en/depts/mayor/press_ room/press_releases/2014/mar/survey-of-divvy-members-brings-positive-reviewsof-chicagos-newe.html, retrieved March 5, 2015.

Crowley, D. F., A. S. Shalaby, and H. Zarei. 2009. "Access Walking Distance, Transit Use, and Transit-Oriented Development in North York City Center, Toronto, Canada." Transportation Research Record, 2110: 96-105. doi:10.3141/2110-12.

DeMaio, P. 2009. "Bike-sharing: History, Impacts, Models of Provision, and Future." Journal of Public Transportation, 12(4): 41-56. doi:10.1016/0965-8564(93)90040-R.

Demaio, P., and J. Gifford. 2004. "Will Smart Bikes Succeed as Public Transportation in the United States?" Journal of Public Transportation, 7(2): 1-15.

Dill, J., T. Goddard, C. M. Monsere, and N. McNeil. 2015. "Can Protected Bike Lanes Help Close the Gender Gap in Cycling ? Lessons from Five Cities." Compendium of TRB 94th Annual Meeting, 8581). Washington, DC: Transportation Research Board.

Duthie, J., J. Brady, A. Mills, and R. Machemehl. 2010. "Effects of On-Street Bicycle Facility Configuration on Bicyclist and Motorist Behavior." Transportation Research Record, 2190(-1): 37-44. doi:10.3141/2190-05

Duvall, A. L., and D. Main. 2012. "Public Bicycle Sharing as a Population-Scale Health Intervention for Active Transportation in Denver, Colorado." Health and Behavioral Sciences, University of Colorado Denver.

Faghih-Imani, A., and N. Eluru. 2015a. "Analysing Bicycle-Sharing System User Destination Choice Preferences: Chicago's Divvy System." Journal of Transport Geography, 44: 53-64. doi:10.1016/j.jtrangeo.2015.03.005.

Faghih-Imani, A., and N. Eluru. 2015b. "Analysing Destination Choice Preferences in Bicycle Sharing Systems: An Investigation of Chicago's Divvy System." Compendium of TRB 94th Annual Meeting, 6270. Washington, DC: Transportation Research Board.

Fan, W. (David), and R. B. Machemehl. 2011. "Bi-Level Optimization Model for Public Transportation Network Redesign Problem." Transportation Research Record, 2263: 151-162. doi:10.3141/2263-17. 
Fishman, E., S. Washington, and N. Haworth. 2013. "Bike Share: A Synthesis of the Literature." Transport Reviews, 33(2): 148-165. doi:10.1080/01441647.2013.775612.

Flamm, B. J. 2013. "Determinants of Bicycle-On-Bus Boardings : A Case Study of the Greater Cleveland RTA." Journal of Public Transportation, 16(2): 67-84.

Flyvbjerg, B. 2006. "Five Misunderstandings About Case-Study Research." Qualitative Inquiry, 12(2): 219-245. doi:10.1177/1077800405284363.

Friedmann, J. 1987. "Two Centuries of Planning Theory: An Overview." In Planning in the Public Domain. Princeton, NJ: Princeton University Press.

Hamre, A., and R. Buehler. 2014. "Commuter Mode Choice and Free Car Parking, Public Transportation Benefits, Showers/Lockers, and Bike Parking at Work: Evidence from the Washington, DC Region." Journal of Public Transportation, 17(2): 67-91.

Handy, S., Y. Xing, and T. Buehler. 2010. "Factors Associated with Bicycle Ownership and Use: A Study of Six Small U.S. Cities." Transportation, 37(6): 967-985. doi:10.1007/ s11116-010-9269-x.

Heinen, E., K. Maat, and B. van Wee. 2011. "Day-to-Day Choice to Commute or Not by Bicycle." Transportation Research Record, 2230(-1): 9-18. doi:10.3141/2230-02.

Illinois Department of Transportation. 2014. "Illinois Bike Transportation Plan Executive Summary." Chicago.

Institute of Transportation Engineers. 2010. "Designing Walkable Urban Thoroughfares: A Context Sensitive Approach." Institute of Transportation Engineers.

Iseki, H., and M. Tingstrom. 2014. "A New Approach for Bikeshed Analysis with Consideration of Topography, Street Connectivity, and Energy Consumption." Computers, Environment and Urban Systems, 48: 166-177. doi:10.1016/j. compenvurbsys.2014.07.008.

Krizek, K. J., S. L. Handy, and A. Forsyth. 2009. “Explaining Changes in Walking and Bicycling Behavior: Challenges for Transportation Research." Environment and Planning B: Planning and Design: 725-740.

Krizek, K. J., and E. W. Stonebraker. 2010. "Bicycling and Transit." Transportation Research Record, 2144(-1): 161-167. doi:10.3141/2144-18.

Lopez, L. C. 2015. “City's Bike Share Program Gets Rolling." El Paso Times, September 16.

Ma, T., C. Liu, and S. Erdoğan. 2015. "Bicycle Sharing and Transit: Does Capital Bikeshare Affect Metrorail Ridership in Washington, D.C.?" Compendium of TRB 94th Annual Meeting: 1-21.

Mahmoud, M. S., W. El-Assi, and K. N. Habib. 2015. "Effects of Built Environment and Weather on Bike Sharing Demand: Station Level Analysis of Commercial Bike Sharing in Toronto." Compendium of TRB 94th Annual Meeting: 1-15.

Martin, E. W., and S. A. Shaheen. 2014. "Evaluating Public Transit Modal Shift Dynamics in Response to Bikesharing: A Tale of Two U.S. Cities." Journal of Transport Geography: 315-324. doi:10.1016/j.jtrangeo.2014.06.026. 
Mayor's Bicycle Advisory Council. 2006. Bike 2015 Plan, Chicago, IL.

Mullan, E. 2013. "Exercise, Weather, Safety, and Public Attitudes: A Qualitative Exploration of Leisure Cyclists' Views on Cycling for Transport." SAGE Open, 3(3). doi:10.1177/2158244013497030.

National Association of City Transportation Officials. 2014. NACTO Urban Bikeway Design Guide (Second ed.). Washington, DC: Island Press.

O'Brien, O. 2015. Bike Share Map. http://bikes.oobrien.com/, retrieved November 8, 2015.

Opinion Analysts Inc. 2014. Austin B-cycle Member Survey-April 2014.

Orrick, P., K. Frick, and D. R. Ragland. 2011. "Bicycle Infrastructure That Extends Beyond the Door: Examining Investments in Bicycle-Oriented Design Through a Qualitative Survey of Commercial Building Owners and Tenants." TRB 90th Annual Meeting Compendium of Papers: 1-11.

Pucher, J., and R. Buehler. 2009. "Integrating Bicycling and Public Transport in North America." Journal of Public Transportation, 12(3): 79-104.

Ramsey, K., and A. Bell. 2014. Smart Location Database. Washington, DC: U.S. EPA Office of Sustainable Communities.

Richter, J., M. Friman, and T. Gärling. 2011. "Soft Transport Policy Measures: Gaps in Knowledge." International Journal of Sustainable Transportation, 5(4): 199-215. doi:1 0.1080/15568318.2010.490289.

Rodriguez, D. B., and N. Shoked. 2014. "Comparative Local Government Law in Motion: How Different Local Government Law Regimes Affects Global Cities' Bike Share Plans." Fordham Urban Law Journal, 42(123): 123-191.

Shaheen, S. A., A. P. Cohen, and E. W. Martin. 2013. "Public Bikesharing in North America." Transportation Research Record, 2387: 83-92. doi:10.3141/2387-10.

Stevens, M. R. 2013. "Evaluating the Quality of Official Community Plans in Southern British Columbia." Journal of Planning Education and Research, 33(4): 471-490. doi:10.1177/0739456X13505649.

Steiner, F. R., K. S. Butler, and American Planning Association, eds. 2006. Planning and Urban Design Standards (Student). Hoboken, NJ: John Wiley and Sons.

Stevens, M. R., W. Lyles, and P. R. Berke. 2014. "Measuring and Reporting Intercoder Reliability in Plan Quality Evaluation Research." Journal of Planning Education and Research, 34(1). doi:10.1177/0739456X13513614.

Taylor, D., and H. Hahmassani. 1996. "Analysis of Stated Preferences for Intermodal Bicycle-Transit Interfaces." Transportation Research Record, 1556: 86-95.

Thompson, G. L., J. R. Brown, R. Sharma, and S. Scheib. 2006. "Where Transit Use is Growing : Surprising Results." Journal of Public Transportation, 9(2): 25-43. 
Tolbert, P. 2014. "Austinites Defeat Urban Rail Transportation Bond." http://kxan. com/2014/11/04/austinites-defeat-urban-rail-transportation-bond/ retrieved May 20, 2012.

Twaddle, H., F. Hall, and B. Bracic. 2010. "Latent Bicycle Commuting Demand and Effects of Gender on Commuter Cycling and Accident Rates." Transportation Research Record, 2190: 28-36. doi:10.3141/2190-04.

U.S. Census Bureau. 2013a. "American Community Survey 1-Year Estimates." http:// factfinder2.census.gov/.

U.S. Census Bureau. 2013b. "American FactFinder-Community Facts." http://factfinder. census.gov/faces/nav/jsf/pages/community_facts.xhtml, retrieved May 4, 2015.

Vance, S. 2014. "More Women Signing Up for Divvy, But Not Necessarily Riding." Streetsblog Chicago. http://chi.streetsblog.org/2014/09/05/more-women-signing-upfor-divvy-but-not-necessarily-riding/, retrieved April 20, 2012.

Wang, R., and C. Liu. 2013. "Bicycle-Transit Integration in the United States, 2001-2009." Journal of Public Transportation, 16(3): 95-119.

Wear, B. 2014. "Bergstrom Expressway, Other Austin Tollway Projects Gather Steam." Austin American-Statesman, March 30.

Willson, R. 2001. "Assessing Communicative Rationality as a Transportation Planning Paradigm." Transportation, 28(1): 1-31. doi:10.1023/a:1005247430522.

Willson, R. W., M. Payne, and E. Smith. 2003. "Does Discussion Enhance Rationality? A Report from Transportation Planning Practice." Journal of the American Planning Association, 69(4): 354-367.

Winters, M., M. Brauer, E. M. Setton, and K. Teschke. 2010. "Built Environment Influences on Healthy Transportation Choices: Bicycling versus Driving." Journal of Urban Health, 87(6): 969-993. doi:10.1007/s11524-010-9509-6.

\section{About the Authors}

GReg Phillip GRIffin, AICP (g-griffin@tti.tamu.edu), is a researcher in the Austin office of the Texas A\&M Transportation Institute, following more than a decade of experience in public and private sector planning and geographic information systems. He is pursuing a Ph.D. in Community and Regional Planning at The University of Texas at Austin and is leading a study of real-time ridesharing technology with tolling discounts and developing new methods to assess active transportation.

IPeK Nese Sener, Ph.D. (i-sener@tti.tamu.edu), is a researcher in the Austin office of the Texas A\&M Transportation Institute and has more than 10 years of research experience in advancing the state-of-art and state-of-practice in the area of transportation modeling and activity-travel behavior analysis. She received a doctorate in Transportation Engineering from The University of Texas at Austin (2010) and M.S. degrees in Civil Engineering (2005) and Architecture (2004) and a B.S. degree in Civil Engineering (2002) from the Middle East Technical University in Ankara, Turkey. Her 
focus is on the development, application, validation, and application of travel demand modeling systems in support of different economic, financial, environmental, and health analyses. She currently is working as TTI's lead for a five-year National Institutes of Health project examining the effects of light-rail transit on physical activity and travel behavior. 